\title{
Evaluation of Whole-Body-Vibration Exposure to Cairo Subway (Metro) Passengers
}

\author{
Manal El Sayed \\ Department of \\ Communications, Electronics \\ and Computers \\ Faculty of Engineering, Helwan \\ University, Cairo, Egypt
}

\author{
Shahira Habashy \\ Department of \\ Communications, Electronics \\ and Computers \\ Faculty of Engineering, Helwan \\ University, Cairo, Egypt
}

\author{
Mohamed El Adawy \\ Department of \\ Communications, Electronics \\ and Computers \\ Faculty of Engineering, Helwan \\ University, Cairo, Egypt
}

\begin{abstract}
Vehicles (air, land and water), machinery (for example, those used in industry and agriculture) and industrial activities (such as pilling and blasting), expose people to periodic, random and transient mechanical vibration which can interfere with comfort, activities and health. Metro is one of the important and famous public transportations all over the world. High magnitude of whole-body vibration formed by the Metro may cause diseases and health problems to the human especially a low back pain. It leads to a muscular and bone system disorder of the neck and back. A previous epidemiological study reported that low-back pain (LBP) is spread among people exposed to whole-body-vibration frequently. LBP was significantly related with the levels of uncomfortable road vibrations, and, importantly, increased with total mileage. The aim of this study is to give an account of daily exposure to vibration and vibration dose value exposed to the passengers travelled using Cairo metro by measuring the whole body vibration on the passenger's seat pan (seat back and seat surface) and on the floor. The results were evaluated according to the health guidelines of the international standards ISO 2631-1:1997, Directive 2002/44/EC of the European Parliament and ISO 2631-5:2004.
\end{abstract}

\section{General Terms}

Evaluation of Whole Body Vibration.

\section{Keywords}

Whole-body vibration (WBV), vibration dose value (VDV), low back pain (LBP), ISO 2631-1:1997.

\section{INTRODUCTION}

Our bodies are exposed to vibration in all transportation means. Vibration has been proven to result in musculoskeletal disorders of the shoulders, the neck, and the back. Along with musculoskeletal problems, exposure to whole-body vibration also presents a health risk to the psychomotor, physiological, and psychological systems of the body. Whole body vibration is transmitted to the body through the supporting surfaces such as the feet, buttocks or back. Vibration is often complex, contains many frequencies, occurs in several directions and changes over time. The effects of vibration may be manifold. Exposure to whole-body vibration causes a complex distribution of oscillatory motions and forces within the body. There can be large variations between subjects with respect to biological effect. Whole-body vibration may cause sensations (e.g. discomfort or annoyance), influence human performance capability or present a health and safety risk (e.g. pathological damage or physiological change). The presence of oscillatory force with little motion may cause similar effects. The effects of direct vibration on the human body can be serious. Vibration can typically cause blurred vision, loss of balance, loss of concentration etc. In some cases, certain frequencies and levels of vibration can permanently damage internal body organs. After daily exposure over a number of years, these same whole-body vibrations can result in a number of health disorders affecting your entire body including permanent harm to internal organs, muscles, joints and bone structure. Research indicates back disorders are more prevalent and more severe in exposed to vibration versus non-exposed. With short term exposure to vibration in the $2-20 \mathrm{~Hz}$ range at 1 $\mathrm{m} / \mathrm{sec}^{2}$, one can feel several different symptoms like, [16] abdominal pain, general feeling of discomfort, including headaches, chest pain, Loss of equilibrium (balance), muscle contractions with decreased performance in precise manipulation tasks, shortness of breath, and influence on speech.

Long-term exposure can cause serious health problems, particularly with the spine like, disc displacement, degenerative spinal changes, lumbar scoliosis, intervertebral disc disease, degenerative disorders of the spine, herniated discs, disorders of the gastrointestinal system, and uro-genital systems.

Various definitions have been given to Whole-Body Vibration, WBV, by dictionaries, companies and authors themselves. From the Directive 2002/44/EC of the European Parliament and of the Council, the term 'whole-body vibration' means the mechanical vibration that, when transmitted to the whole body, entails risks to the health and safety of workers, in particular lower back morbidity and trauma of the spine (EC, 2000). WBV is defined as vibration occurring when a greater part of the body weight is supported on a vibrating surface. WBV principally occurs in vehicles and wheeled working machines. In most cases exposure to WBV occurs in a sitting position and the vibration is then primarily transmitted through the seat pan, but also through the back rest [1]. Low Back Pain, LBP, is among the most common and costly health problems [2,3]. Occupational, nonoccupational and individual risk factors play a role in the development, the duration and the recurrence of LBP. Several critical reviews have discussed the evidence on occupational 
risk factors for back disorders [4-8]. All these reviews conclude that there is strong epidemiological evidence for a relation between occupational exposure to WBV and LBP. In five European countries (Belgium, Germany, Netherlands, France, Denmark), LBP and spinal disorders due to WBV are currently recognized as an occupational disease (Hulshof et al., 2002). However, high exposures and adverse effects still occur as WBV is a common occupational risk factor for LBP, affecting $4-8 \%$ of the workforce in industrialized countries (Palmer et al., 2000). Important high risk groups are drivers of off-road vehicles (for example, earth moving, forestry and agricultural machines), drivers of forklift trucks, lorries, or buses, crane operators and helicopter pilots. [19]

In order to prevent negative health outcomes associated with WBV exposure, a risk assessment, based on published standards, can be conducted. The most widely accepted standard for measurement and evaluation of human exposure to WBV and subsequent prediction of health risks is the International Organization of Standards (1997) report entitled ISO 2631-1: Mechanical vibration and shock-Evaluation of human exposure to whole-body vibration, Part 1-General requirements. This standard provides guidance on the quantification of WBV in relation to human health and comfort, the probability of vibration perception, and incidence of motion sickness. In 2004 the International Organization for Standardization introduced a new standard for the evaluation of human exposure to WBV that contains multiple shocks, called ISO 2631-5: Mechanical vibration and shockEvaluation of human exposure to whole-body vibration, Part5-Method for evaluation of vibration containing multiple shocks. The foundation for the new standard was laid by a series of research reports commissioned by the United States Army Aero medical Research Laboratory between 1991 and 1997. The new ISO standard was established to quantify health risks specifically to the lumbar spine and the vertebral endplates as a result of WBV exposures containing multiple shocks. [18]

The rest of the paper is organized as follows Section II outlines the general architecture and design of the system prototype and defines the role of each component. Section III presents the measurement tests of WBV. Section IV presents results and mathematical definition of evaluation methods. Section V presents discussion of the results and compares it with the threshold limit values defined in the standards. Section VI summarizes and concludes the paper.

\section{System Description}

With the advances in inexpensive miniature sensors, embedded microcontrollers, and wireless networking technologies, there has been a growing interest in using wireless sensor networks in medical applications. For example, wireless sensor networks can replace expensive and cumbersome wired devices for pre-hospital and ambulatory emergency care when real-time and continuous monitoring of vital signs is needed. In this section, we describe the design of a wireless body sensor system that consists of a wearable sensor unit and a data logger unit, as shown in fig. 1. The wearable Micromachined Accelerometer (MMA7361L) sensor unit is carried by a person at the contact points. It acquires the vibration signals. The measured data are fed into a microcontroller and sampled via an analog-to-digital converter (ADC). The sampled data are then transmitted wirelessly to the data logger unit, which is connected to a computer through a USB connection. The measured data is analyzed using software programs.

For the purpose of demonstration, we select accelerometers as the monitoring device in the wearable sensor unit. Accelerometers measure both static (e.g., gravity) and dynamic (e.g., vibration) acceleration, both including the always-present gravitational acceleration $\mathrm{g}$. We choose the accelerometer in our design mainly because of its low price, small size, capability of continuous measurement, and ease of integration. In this study, the assessment of whole-body vibration is completed by deciding a sampling rate of 200 samples/sec. This would be enough since it has been found that the frequency range considered for whole body vibration is

- $\quad 0.5 \mathrm{~Hz}$ to $80 \mathrm{~Hz}$ for health, comfort and perception.

- $0.1 \mathrm{~Hz}$ to $0.5 \mathrm{~Hz}$ for motion sickness.

Computation of the exposure time was set to $8 \mathrm{~h}$ for each trip, which equal to the duration for normal occupation stipulation. The study has been conducted at different locations. The total vibration of each axes $\mathrm{x}, \mathrm{y}$ and $\mathrm{z}$ felt by the passenger is displayed in a plotted graph using Matlab software. Wholebody vibration measurement explored by the passenger was done three times at different Metro trip areas.

\subsection{Wearable Sensor Unit}

The Freescale tri-axial analog Micromachined Accelerometer (MMA7361L) is selected as the measurement device on the wearable sensor unit. This accelerometer has two different measurement ranges $( \pm 1.5 \mathrm{~g}$ and $\pm 6.0 \mathrm{~g})$ that can be dynamically set by one input pin (table 1). Each range provides different measurement sensitivity levels. The accelerometer continuously records accelerations in all three axes. The lower ranges (e.g., $\pm 1.5 \mathrm{~g}$ ) are used primarily for accurate measurements of small motions, whereas the higher ranges (e.g., $\pm 6.0 \mathrm{~g}$ ) are used primarily for measurements of vibration and impact.

Table 1: g-Select Pin Description

\begin{tabular}{|c|c|c|}
\hline g-select & g-range & Sensitivity \\
\hline 0 & $1.5 \mathrm{~g}$ & $800 \mathrm{mV} / \mathrm{g}$ \\
\hline 1 & $6 \mathrm{~g}$ & $206 \mathrm{mV} / \mathrm{g}$ \\
\hline
\end{tabular}

The measured data are read by MICROCHIP PIC18F4520 Enhanced Flash microcontroller with 10-Bit A/D and nanoWatt Technology. The microcontroller does simple processing on the data. 


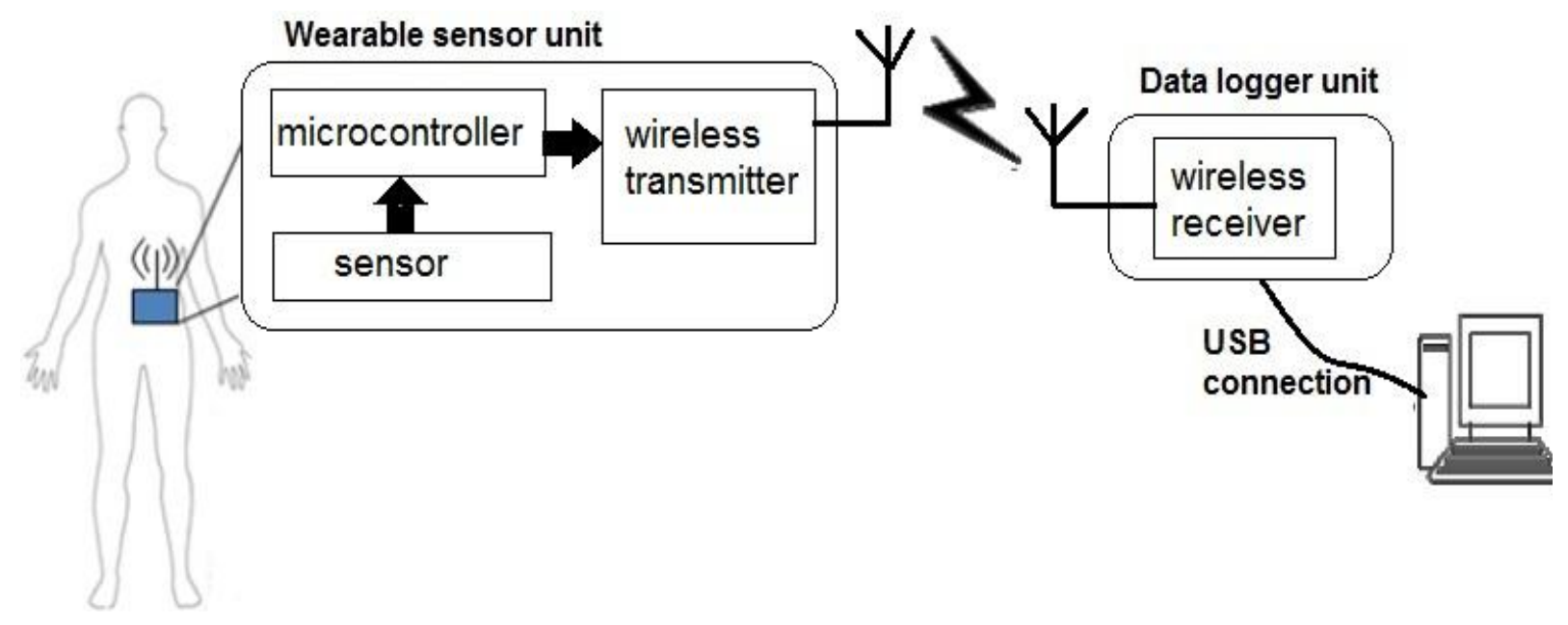

Fig 1: A wireless body sensor system for acceleration measurement.

The processed data are fed to a wireless transceiver and sent wirelessly to the data logger unit, which is connected to PC. The measured data will be downloaded to a PC through a USB connection and analyzed using software programs.

\subsection{Selection of Wireless Standard}

The designed product is expected to be used for short-distance environment; therefore a short- range wireless communication system is more appropriate for this application. Generally, there are two types of wireless communication standards that are suitable for this project: IEEE 802.15.1 (Bluetooth) and IEEE 802.15.4 (ZigBee); both operate in the $2.4 \mathrm{GHz}$ unlicensed frequency (ISM) band.

IEEE standard 802.15.4 specifies the physical layer and medium access control for a type of wireless personal area networks which focuses on low-cost, low-speed ubiquitous communication between devices. It is designed for applications with transmission range up to $100 \mathrm{~m}$ and data transfer rates of 20-250kbps. It is clear that IEEE 802.15.4 (ZigBee) radio modem from MaxStream is the better choice for our proposed design which requires short range wireless communication between low-cost, low-power, batteryoperated devices for monitoring purposes.

\subsection{Data Logger Unit}

With the XBee Explorer dongle you can now plug the unit directly into your USB port. No cables needed! This unit works with all XBee modules. Upon receiving the measurement data from the wireless interface, the processed data will be downloaded to a PC and then serve as the basis for the required calculations and analysis by the developed software.

\section{Methodology}

Vibration measurements were done according to the measuring procedure outlined in ISO 2631-1 (1997), which is also applicable to ISO 2631-5 (2004). Acceleration levels were measured on the passenger seat of the metro (First Line) in three perpendicular directions (seat $\mathrm{x}$ - longitudinal, seat $\mathrm{y}-$ transverse, seat $\mathrm{z}$-vertical, as shown in fig.2) and on the floor beneath the seat. The tri-axial accelerometer sensor was located between the passenger contact points with the vibration source in the direction of translational vibration, the feet of standing person, the buttocks, back and feet of a seated person or the supporting area of recumbent person.
Signals from the tri-axial accelerometer were passed to 3channel of PIC $18 f 4520$ microcontroller ADC which did the digital data recording then pass these data to the wireless transmitter Zigbee module which send these data wirelessly to the other receiver Zigbee module which is directly connected to the computer and start to download the acceleration data for post processing and further analysis. Using MATLAB, three graphs of each axes been meditated for current analysis, as shown in fig.4. Besides, the data and vibration signal can be saved in the personal computer for next analysis. The same data set was used for the analysis using the two standards ISO 2631-1 (1997) and ISO 2631-5 (2004). Standards for WBV exposure specify daily vibration exposure levels (exposure action value, EAV and exposure limit value, ELV), as shown in table 2. Where a passenger is likely to be exposed to vibration, an assessment of the likely daily vibration exposure is to be made. If the exposure level is above the EAV, a range of actions must be taken to reduce exposure and decrease risks. If ELV is exceeded, immediate action must be taken to reduce vibration exposure below the ELV and procedures be implemented to prevent it being exceeded again. Prediction WBV health risks is based on ISO 2631-1 (1997), health guidance caution zone, HGCZ limits, and 2631-5 (2004) are shown in table 2.

Two assessment methods are set out in the standard 2631-1 (1997). The Basic Evaluation method uses weighted rootmean-square (WRMS) acceleration value and compares it with the Health Guidance Caution Zone shown in fig.3. For shock type vibration (jolts and jars) the fourth power vibration dose value (VDV) method is more sensitive to peaks than the basic evaluation method. The standard provides guidelines for exposure durations. The guidance criteria for WRMS and VDV are shown in table2. For exposure below the zone, health effects have not been clearly documented and/or objectively observed; in the zone, caution with respect to health risks is indicated and above the zone health risks are likely, as shown in fig.3. ISO 2631-5 (2004) gives guidelines for the evaluation of vibration containing multiple shocks based on an equivalent Static Compressive Stress (Sed) and Risk Factor $(\mathrm{R})$ values. 


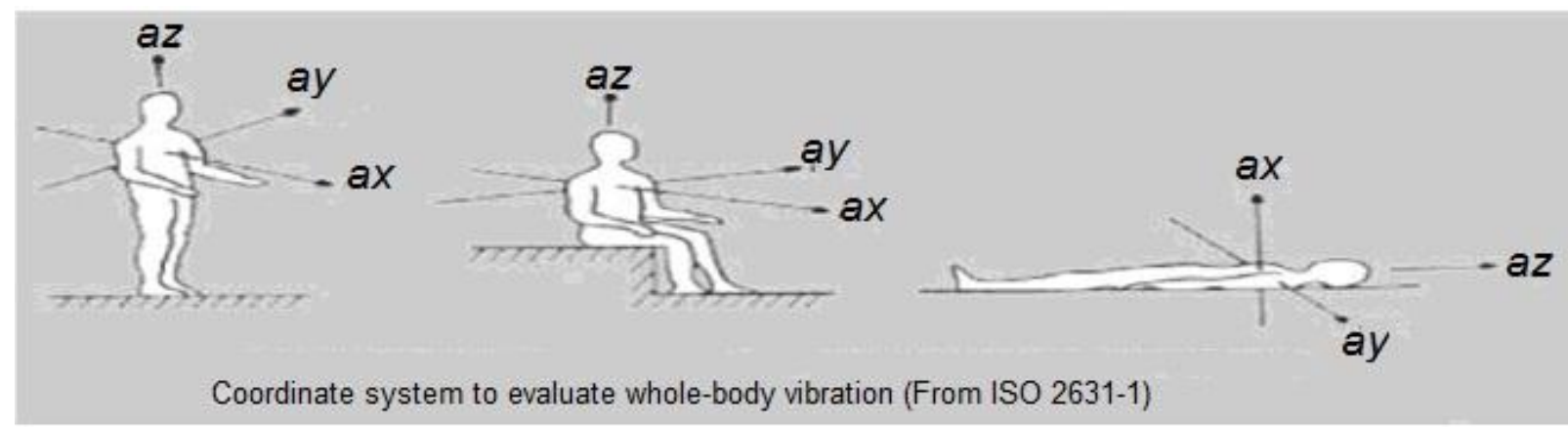

Fig 2: Coordinate system to evaluate whole-body vibration (From ISO 2631). [9]

\subsection{Computation of ISO 2631-1 (1997) parameters}

In accordance with the requirements of ISO 2631-1 (1997) and European Directive 2002, the acceleration time histories recorded to compute the following:

- Measurement of axis-weighted acceleration RMS time histories $\mathrm{a}_{\mathrm{w}}\left(\mathrm{m} / \mathrm{s}^{2}\right)$;

- Estimated passenger daily vibration exposure $A(8)$ $\left(\mathrm{m} / \mathrm{s}^{2}\right)$ and Vibration Dose Value (VDV) $\left(\mathrm{m} / \mathrm{s}^{1.75}\right)$ forms;

- $\quad$ Crest factor CF;

- Time to reach the EAV and ELV, when specified both in daily exposure to vibration $\mathrm{A}(8)$ form;

- Exposure points system.

The data acquired was measured for 20 minutes to 30 minutes. However, this was measured in such a way as to represent the vibration levels experienced by the passenger related to the normal 8-hour work period. The required parameters were then computed and extrapolated to cover the entire duration of exposure. The time domain data was read and then converted to $\mathrm{m} / \mathrm{s} 2$. The data was then weighted according to ISO 2631-1 (1997) whole-body vibration weighting filter. Subsequent to the weighting, the WRMS and VDV parameters were then computed.

\subsection{Computation of ISO 2631-5 (2004) parameters}

The new multiple shocks standard relies on biodynamic models described to calculate acceleration response at the lumbar spine. Dedicated software was also used to compute an equivalent Static Compressive Stress (Sed) and Risk Factor (R) parameters based on ISO 2631-5 (2004). These parameters were then used in predicting risk to health.

\section{Acceleration Measurement Tests}

During the three trips done, the evaluation methods were computed. The mathematical definition of the Weighted Root Mean Square (WRMS), the Crest Factor, daily exposure to vibration $\mathrm{A}(8)$ value, VDV, and exposure points value are calculated using equation (1) to equation (6) based on ISO 2631-1 (1997) and European Directive 2002. [9, 12]

Once the spinal accelerations have been generated, an acceleration dose (Dx, Dy, and Dz) is calculated. The dose then is normalized to an average workday based on duration of the available record and the expected length of the workday, to obtain $D_{x d}, D_{y d}, D_{z d}$ and calculate the total daily exposure. The ISO 2631-5 (2004) provides guidance for assessment of health effects of multiple shocks. Given the calculated total daily acceleration dose in each of the basicentric axes, they are combined to obtain an equivalent static compressive stress $\left(\mathrm{S}_{\text {ed }}\right)$ which is used to compute risk factor, $\mathrm{R}$, for use in the assessment of the adverse health effects. These parameters are calculated using equation (7) to equation (10) based on ISO 2631-5 (2004). [15, 17]

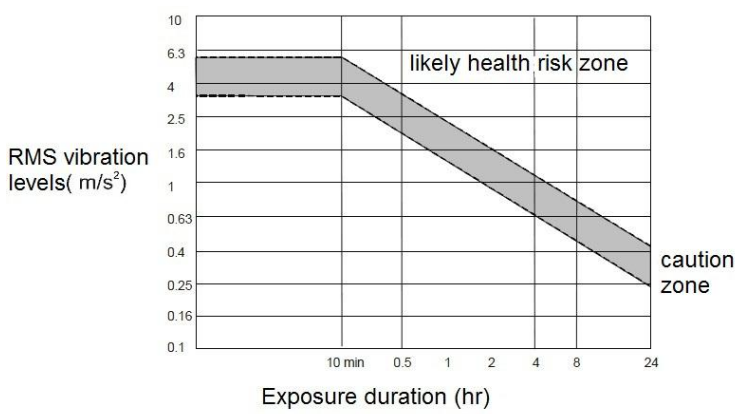

Fig 3: Health Guidance Zones - Basic Method (r.m.s.) [9]

The weighted r.m.s acceleration (WRMS):

It is expressed in $\mathrm{m} / \mathrm{s} 2$ for translational vibration and calculated as follows:

$$
a_{w}=\left[\frac{1}{T} \int_{0}^{T} a_{w}^{2}(t) d t\right]^{\frac{1}{2}}
$$

Where aw (t) is the weighted (see ISO 2631-1 (1997) weighting curve) acceleration time history and $\mathrm{T}$ is the duration of the measurement. [9]

The Crest Factor (CF):

$C F=\left|\frac{\max \left(a_{w}\right)}{a_{w r . m . s}}\right|$ 
Table 2: Exposure action and limit values and health guidance caution zone values for whole-body vibration.

\begin{tabular}{|c|c|c|c|c|c|c|}
\hline \multirow{2}{*}{ Exposure / HGCZ } & \multicolumn{2}{|c|}{ ISO 2631-1 (1997) } & \multicolumn{2}{|c|}{ European Directive 2002} & \multicolumn{2}{|c|}{ ISO 2631-5 (2004) } \\
\hline & WRMS & VDV & WRMS & VDV & Sed & $\mathbf{R}$ \\
\hline EAV / HGCZ lower limit & $0.43 \mathrm{~m} / \mathrm{s} 2$ & $8.5 \mathrm{~m} / \mathrm{s} 1.75$ & $0.50 \mathrm{~m} / \mathrm{s} 2$ & $9.1 \mathrm{~m} / \mathrm{s} 1.75$ & $0.50 \mathrm{MPa}$ & 0.80 \\
\hline ELV / HGCZ upper limit & $0.86 \mathrm{~m} / \mathrm{s} 2$ & $17 \mathrm{~m} / \mathrm{s} 1.75$ & $1.15 \mathrm{~m} / \mathrm{s} 2$ & $21 \mathrm{~m} / \mathrm{s} 1.75$ & $0.80 \mathrm{MPa}$ & 1.20 \\
\hline
\end{tabular}

The Crest Factor is the modulus of the ratio of the maximum instantaneous peak value of the frequency weighted acceleration signal to its r.m.s. value. [9]

Daily exposure to vibration $\mathrm{A}(8)$ :

The 8-hour energy equivalent vibration total value for a worker in meters per second squared $\left(\mathrm{m} / \mathrm{s}^{2}\right)$, including all whole-body vibration exposures during the day.

$$
A_{i}(8)=k a_{w i} \sqrt{\frac{\exp \text { osure time }(\mathrm{min})}{480(\mathrm{~min})}}
$$

Where awi $=$ Frequency-weighted acceleration $(\mathrm{m} / \mathrm{s} 2)$ in the $\mathrm{i}$ direction ( $\mathrm{i}=\mathrm{x}, \mathrm{y}, \mathrm{z})$. [12]

$\mathrm{k}=$ multiplying factor (for $\mathrm{x}$-axis: $\mathrm{k}=1.4, \mathrm{y}$-axis: $\mathrm{k}=1.4$ and z-axis: $\mathrm{k}=1$ ).

Vibration Dose Value (VDV):

A cumulative dose is based on the fourth root of the fourth power of the acceleration signal. VDV has units of $\mathrm{m} / \mathrm{s}^{1.75}$.

$V D V=\left\{\int_{0}^{T}\left[a_{w i}(t)\right]^{4} d t\right\}^{\frac{1}{4}}$

$\mathrm{T}=$ the total period of the day during which vibration may occur(s). [9]

Exposure points value:

For any vehicle or machine operated, the number of exposure points accumulated in an hour $\left(P_{\mathrm{E}, \mathrm{h}}\right.$ in points per hour $)$ can be obtained from the vibration magnitude $a_{\mathrm{w}}$ in $\mathrm{m} / \mathrm{s}^{2}$ and the factor $k$ (either 1.4 for $\mathrm{x}$ - and $\mathrm{y}$-axes or 1.0 for the $\mathrm{z}$-axis) using: [12]

$$
P_{E, 1 h}=50\left(k a_{w}\right)^{2}
$$

In general the number of exposure points, $\mathrm{P}_{\mathrm{E}}$, is defined by: [12]

$$
P_{E}=\left(\frac{k a_{w}}{0.5 m / s^{2}}\right)^{2} \frac{T}{8 \text { hours }} 100
$$

The acceleration dose (Dk):

$$
\boldsymbol{D}_{k}=\left[\sum_{i=1}^{m} A_{i k}^{6}\right]^{1 / 6}
$$

Where $\mathrm{A}_{\mathrm{ik}}$ is the $\mathrm{i}^{\text {th }}$ peak of the acceleration in the $\mathrm{k}$-direction $(\mathrm{k}=\mathrm{x}, \mathrm{y}$ or $\mathrm{z})$, and $\mathrm{m}$ is the number of peaks in the measured signal. $[15,17]$
The average daily dose (Dkd):

$$
D_{k d}=D_{k}\left[\sum_{t} \frac{\boldsymbol{t}_{d}}{\boldsymbol{t}_{m}}\right]^{\frac{1}{6}}
$$

For assessment of health effects the average daily dose, $D_{k d}$, for each direction $\mathrm{k}$ is obtained by normalizing the dose measured over a period $t_{m}$ to the duration of an average workday $t_{d} \cdot[15,17]$

The daily equivalent static compressive stress $\left(\mathrm{S}_{\mathrm{ed}}\right)$ :

$$
\boldsymbol{S}_{e d}=\left[\sum_{k=x, y, z}\left(m_{k} D_{k d}\right)^{6}\right]^{1 / 6}
$$

Where $\mathrm{m}_{\mathrm{k}}$ is empirical constant for $\mathrm{x}, \mathrm{y}$, and $\mathrm{z}$ directions. Recommended values for these constants are: $\mathrm{m}_{\mathrm{x}},=0.015, \mathrm{~m}_{\mathrm{y}}$ $=0.035$ and $\mathrm{m}_{\mathrm{z}}=0,032 \mathrm{MPa} /\left(\mathrm{m} / \mathrm{s}^{2}\right)$. Finally, the health risk for healthy seated males may be projected to a lifetime, using a risk factor R. [15, 17]

The $\mathrm{R}$ factor:

The $\mathrm{R}$ factor is defined for use in adverse health effects related to the human response acceleration dose. $[15,17]$

$$
R=\left[\sum_{i=1}^{n}\left(\frac{S_{e d} \cdot N^{1 / 6}}{S_{u i}-c}\right)^{6}\right]^{1 / 6}
$$

Where $\mathrm{N}$ is the number of exposure days per year; $\mathrm{i}$ is the year counter; $\mathrm{n}$ is the number of years of exposure; $\mathrm{c}$ is a constant representing the static stress due to gravitational force (a value of $\mathrm{c}=0.25 \mathrm{MPa}$ can be normally used for driving posture); $\mathrm{S}_{\mathrm{ui}}$ is the ultimate strength of the lumbar spine for a person of age $(b+i)$ years; $b$ is the age at which exposure starts. From invitro studies [15], the following relationship between $S_{u i}$ (in $\mathrm{MPa}$ ) and $\mathrm{b}+\mathrm{i}$ (in years) had been derived:

$$
\mathrm{S}_{\mathrm{ui}}=6.75-0.066(\mathrm{~b}+\mathrm{i}) \text {. }
$$

Three trips are done in the metro of the first line, ElmargHelwan, (in normal conditions) between semi-crowded and crowded situations. For the first trip the graph of whole-body vibration was collected namely from EL-Marg to Ghamra, while the second trip was from Helwan to Mar-gergis and the third trip from Ahmed Orabi to Hada'k Helwan. All the results obtained in the three trips were shown in table 3 and table 4 . Whole-body vibration graphs for the first trip were demonstrated in fig. 4. 

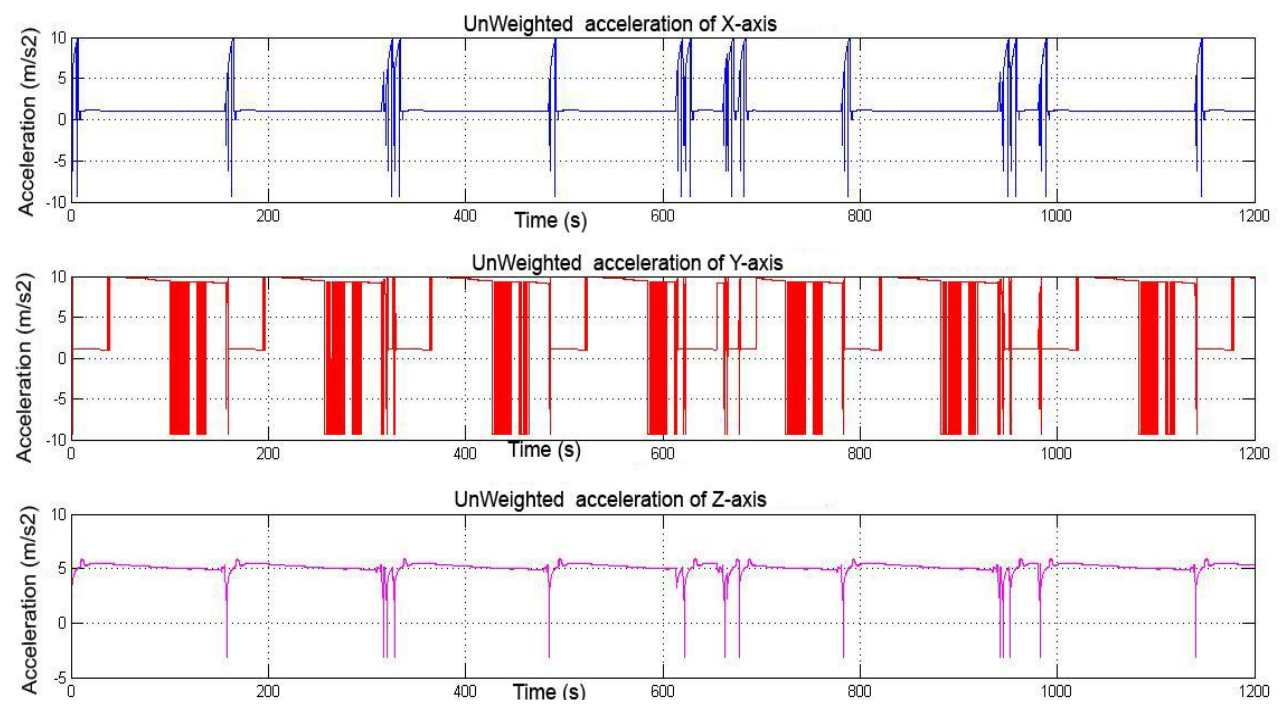

Fig 4: Unweighted acceleration during First metro trip in $x, y, z$ directions.

\section{Discussion}

Time domain accelerations for selected trips in Cairo Metro are shown in fig.4. These time histories were used in the computation of the WRMS and VDV based on ISO 2631-1 (1997). It can be seen that shocks are present in these time acceleration histories. The shocks range roughly between -9 $\mathrm{m} / \mathrm{s}^{2}$ and $9 \mathrm{~m} / \mathrm{s}^{2}$. For integration of the frequency-weighted acceleration time history, the frequency weighting shall be determined as appropriate. The frequency range of measured signal was obtained by conducting an FFT analysis on that signal; fig. 5 shows the power of the DFT of $\mathrm{x}$-direction of the first trip.

The data from table 2 indicates the frequency weighted acceleration value that was suggested by the ISO 2631-1 (1997) standard as guidelines. If the WRMS value is less than $0.43 \mathrm{~m} / \mathrm{sec}^{2}$ then this shows that there is no negative health effects expected. Whilst the frequency weighted value is in between 0.43 and $0.86 \mathrm{~m} / \mathrm{sec}^{2}$ then the negative health effects still can be accepted. If the frequency weighted acceleration value is greater than $0.86 \mathrm{~m} / \mathrm{sec}^{2}$ then this indicates high risks of bad health problems were anticipated. The European Directive 2002 suggests the Daily vibration exposure A(8) value which equal $0.5 \mathrm{~m} / \mathrm{sec}^{2}$ (EAV) showed that there was negative health effect expected and a range of actions must be taken to reduce exposure and decrease risks. Daily vibration exposure $\mathrm{A}(8)$ value which is equal or greater than 1.15 $\mathrm{m} / \mathrm{sec}^{2}$ indicates that the negative health effects are exceeded, so immediate action must be taken to reduce vibration exposure below the ELV. The ISO 2631-5 (2004) suggests that $\mathrm{R}<0.8$ indicates a low probability of an adverse health effect and $\mathrm{R}>1.2$ indicates a high probability on an adverse health effect. This is equivalent to stating that $S_{\text {ed }}=0.5 \mathrm{MPa}$ and $\mathrm{S}_{\mathrm{ed}}=0.8 \mathrm{MPa}$ are the lower and upper boundary of a caution zone for a normal person during a typical working day.

Results of the WBV analysis using frequency weighted RMS accelerations (table 3 ) indicated that the frequency weighted acceleration WRMS value along three trips exceeded the ISO 2631 (1997) guidelines approximately at the seat and the floor for each axis (X-axis: Range from $0.4209 \mathrm{~m} / \mathrm{s}^{2}$ to $0.5631 \mathrm{~m} / \mathrm{s}^{2}$, Y-Axis: Range from $0.56 \mathrm{~m} / \mathrm{s}^{2}$ to $1.3052 \mathrm{~m} / \mathrm{s}^{2}$, Z-Axis: Range from $1.2825 \mathrm{~m} / \mathrm{s}^{2}$ to $1.7862 \mathrm{~m} / \mathrm{s}^{2}$ ). Also Partial Daily vibration exposure $\mathrm{A}(8)$ value indicated in the study of each trip (Highest axis) was closely to the permissible value of exposure action value, EAV, stated according to European Directive 2002 but Total daily vibration exposure A(8) (the vector sum through the highest axis) was more than the permissible value of the EAV. Therefore, the high magnitude of WBV may cause musculoskeletal disorders to the metro passengers.

ISO 2631-1 (1997) states that for CF higher than 9; an additional parameter vibration dose value, VDV, needs to be calculated because the shock content of the vibration is high. The data from table 3 shows that most of the CFs are higher than 9 and some others are very close to 9 . Due to frequent shocks the additional parameter VDV was calculated as shown in table 3. The highest axis of VDV is Z-axis in the first and second trips and it is $\mathrm{Y}$-axis in the third trip. For the first and second trips the VDV was more closely to the permissible value of exposure limit value, ELV, which stated according to ISO 2631-1 (1997), but in the third trip it is exceeded the ELV. The vector sum of VDV for three trips (Total vibration dose value) was $21.78 \mathrm{~m} / \mathrm{s}^{1.75}$ in Z-axis which is greater than exposure limit value. This indicates that the metro passengers are at an increased risk of adverse health. The risk results from the dose of WBV during trips which take approximately 70 minutes per day. Also, the results of the third trip indicated that the values of daily vibration exposure $\mathrm{A}(8)$ and Vibration Dose Value, VDV were much higher than the first and second trips. The values of daily exposure to vibration $\mathrm{A}(8)$ and Vibration Dose Value(VDV), were $0.46 \mathrm{~m} / \mathrm{sec}^{2}$ and $19.93 \mathrm{~m} / \mathrm{sec}^{1.75}$ respectively. It seems possible that these results were due to indelicate track passed by the train, the train operation style and speed differences compared to first and second trips. In addition, the daily 

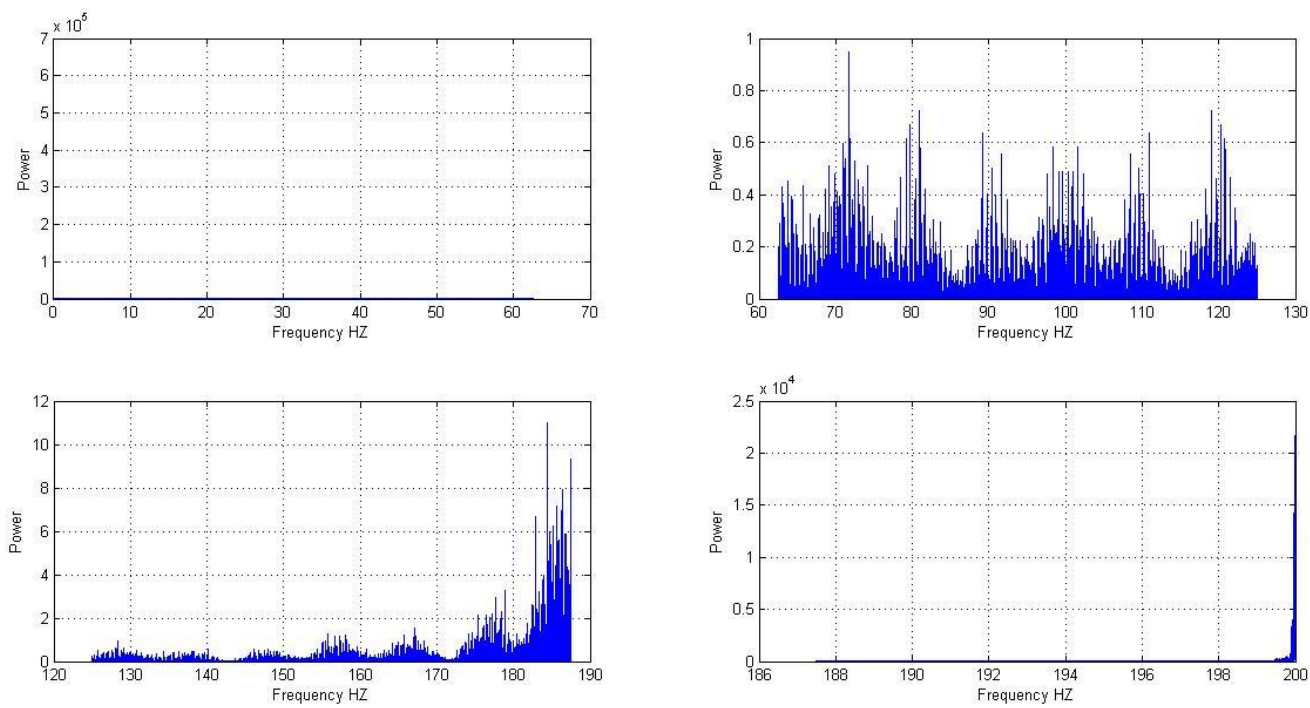

Fig 5: Power of the DFT in $x$-direction for the first metro trip

exposure action value time required 35 min only to meet the standardized value of $0.5 \mathrm{~m} / \mathrm{sec}^{2}$ to an $8 \mathrm{~h}$ reference period (in safe conditions).

The reasons for this high magnitude of vibration value may be due to the speed of the train, the age, and the needed maintenance for it. That high magnitude of whole-body vibration exposure produced by the metro will contribute to musculoskeletal disorders to the passengers.

There is another evaluation method mentioned in European Directive 2002 indicates that Whole-body vibration exposure management can be simplified by using an exposure "points" system. For any vehicle or machine operated, the number of exposure points accumulated in an hour $\left(\mathrm{P}_{\mathrm{E}, 1 \mathrm{~h}}\right.$ in points per hour) can be calculated using equation (5). Exposure points are simply added together, so you can set a maximum number of exposure points for any person in one day. The exposure scores corresponding to the exposure action and limiting values are: [20]

- Exposure action value $\left(0.5 \mathrm{~m} / \mathrm{s}^{2}\right)=100$ points;

- Exposure limit value $\left(1.15 \mathrm{~m} / \mathrm{s}^{2}\right)=529$ points. In general the number of exposure points, $\mathrm{P}_{\mathrm{E}}$, is defined by equation (6). This way also was used in WBV evaluation. The results show that the total exposure points (sum) were 106 and 153 points in $\mathrm{Y}$ and $\mathrm{Z}$ axes respectively. These values are above 100 points which exceed the permissible EAV of daily exposure vibration points. The highest value of the three axes values is the daily vibration exposure in points.

Total Daily vibration exposure $\mathrm{A}(8)$ for each axis is:
$A_{x}(8)=0.28 \mathrm{~m} / \mathrm{s}^{2}$
$\mathrm{A}_{\mathrm{z}}(8)=0.62 \mathrm{~m} / \mathrm{s}^{2}$
$\mathrm{A}_{\mathrm{y}}(8)=0.51 \mathrm{~m} / \mathrm{s}^{2}$

The whole-body vibration exposure is the highest axis $\mathrm{A}(8)$ value, in this case the value for the $\mathrm{z}$-axe $0.62 \mathrm{~m} / \mathrm{s}^{2}$, i.e. above the exposure action value.
Total Daily vibration dose value exposure for each axis is:

$$
\begin{aligned}
& \operatorname{VDV}_{\mathrm{x}}=16.02 \mathrm{~m} / \mathrm{s}^{1.75} \quad \operatorname{VDV}_{\mathrm{y}}=20.41 \mathrm{~m} / \mathrm{s}^{1.75} \\
& \operatorname{VDV}_{\mathrm{z}}=21.78 \mathrm{~m} / \mathrm{s}^{1.75}
\end{aligned}
$$

The whole-body vibration exposure is highest axis VDV in this case the value for the $\mathrm{z}$-axe $21.78 \mathrm{~m} / \mathrm{s}^{1.75}$, i.e. above the exposure action value.

Total Daily vibration exposure points, for each axis are:

$\mathrm{x}$-axis $=31$ points $\quad \mathrm{y}$-axis $=106$ points

$\mathrm{z}$-axis $=153$ points

The whole-body vibration exposure is highest axis points value, in this case the value for the z-axe 153 points, i.e. above the exposure action value 100 point.

The calculation of the risk factor, $\mathrm{R}$, takes into account the number of years and days per year of exposure and factors in the vertebral bone ultimate strength which depends on the age of the operator at the time of exposure. The calculated values of $\mathrm{R}$ and $\mathrm{S}_{\text {ed }}$ factors during three trips (table 4) were more than the permissible value of the ELV (above the HGCZ upper limit value). Therefore, long term exposure to these types of vibration accelerates onset of lumbar spin disorders and possibly adversely affects the gastro-intestinal and cardiovascular systems and gives an indication of high probability of an adverse health effect. The most pronounced and common effect is lower back pain. This can be linked to the vibration acting on the musculo-skeletal system of the body, causing the degeneration of the small cartilage (intervertebral) discs, allowing tissues and nerves to be strained and pinched leading to various back and neck problems. Long periods of sitting while the spinal column is being aggravated by vibration exposure cause the nutrients needed for growth and repair to diffuse outwards. This causes irreparable damage at a cellular level and wear and reduced healing of discs and vertebra within the spinal column. 
Table 3. Calculations of whole-body vibration levels based on ISO 2631-1 (1997) and European Directive 2002 using WRMS parameter.

\begin{tabular}{|c|c|c|c|c|c|c|c|c|c|}
\hline \multirow[b]{3}{*}{ Analysis method } & \multicolumn{3}{|c|}{ Trip 1 (sitting-20 min) } & \multicolumn{3}{|c|}{ Trip 2 (standing-20 min) } & \multicolumn{3}{|c|}{ Trip 3 (sitting-30 min) } \\
\hline & \multicolumn{2}{|c|}{$\begin{array}{c}\text { from } \\
\text { EL-Marg }\end{array}$} & $\begin{array}{c}\text { to } \\
\text { Ghamra }\end{array}$ & \multirow[t]{2}{*}{$\begin{array}{c}\text { from } \\
\text { Helwar }\end{array}$} & \multicolumn{2}{|c|}{$\begin{array}{c}\text { to } \\
\text { Mar-gergis }\end{array}$} & $\begin{array}{c}\text { from } \\
\text { Ahmed } \\
\text { Orabi } \\
\end{array}$ & \multicolumn{2}{|c|}{\begin{tabular}{c|c} 
to \\
Hada'k \\
Helwan
\end{tabular}} \\
\hline & $\mathbf{x}$ & $\mathbf{y}$ & $\mathbf{z}$ & & $\mathbf{y}$ & $\mathbf{z}$ & $\mathbf{x}$ & $\mathbf{y}$ & $\mathbf{z}$ \\
\hline WRMS aw $(\mathrm{m} / \mathrm{s} 2)$ & 0.5631 & 0.6014 & 1.7862 & 0.4209 & 0.57 & 1.2825 & 0.5455 & 1.3052 & 1.6973 \\
\hline Crest Factor (CF) & 17.88 & 8.78 & 3.21 & 17.91 & 17.32 & 8.03 & 18.28 & 7.47 & 3.31 \\
\hline $\begin{array}{l}\text { Partial Dialy vibration Exposures } \\
\mathrm{A}(8)(\mathrm{m} / \mathrm{s} 2)\end{array}$ & 0.16 & 0.17 & 0.36 & 0.12 & 0.16 & 0.26 & 0.19 & 0.46 & 0.42 \\
\hline $\begin{array}{l}\text { Time (min) to reach Daily } \\
\text { exposure action value ( } 0.5 \\
\mathrm{~m} / \mathrm{sec} 2 \text { ) (for hieghest axis) }\end{array}$ & \multicolumn{3}{|c|}{37.61} & \multicolumn{3}{|c|}{72.96} & \multicolumn{3}{|c|}{35.94} \\
\hline $\begin{array}{l}\text { Time (min) to reach Daily } \\
\text { exposure limit value ( } 1.15 \\
\mathrm{~m} / \mathrm{sec} 2 \text { ) (for hieghest axis) }\end{array}$ & \multicolumn{3}{|c|}{198.97} & \multicolumn{3}{|c|}{385.94} & \multicolumn{3}{|c|}{190.12} \\
\hline $\begin{array}{l}\text { Dialy vibration Exposure points } \\
\text { system }\end{array}$ & 10 & 12 & 53 & 6 & 11 & 27 & 15 & 83 & 72 \\
\hline Points per hour & \multicolumn{3}{|c|}{160} & \multicolumn{3}{|c|}{82} & \multicolumn{3}{|c|}{167} \\
\hline $\begin{array}{l}\text { Fourth Power vibration dose } \\
\text { value }(\mathrm{m} / \mathrm{s} 1.75)\end{array}$ & 12.835 & 6.7912 & 16.2768 & 7.4133 & 10.7975 & 16.2141 & 13.7464 & 19.9342 & 17.1012 \\
\hline
\end{tabular}

Table 4: Calculation of ISO 2631-5 (2004) parameters for Whole-body vibration measurement data collected in metro

\begin{tabular}{|c|c|c|c|c|c|c|c|c|c|}
\hline \multirow[b]{3}{*}{ Analysis method } & \multicolumn{3}{|c|}{ Trip 1 (sitting-20 min) } & \multicolumn{3}{|c|}{ Trip 2 (standing-20 min) } & \multicolumn{3}{|c|}{ Trip 3 (sitting-30 min) } \\
\hline & \multicolumn{2}{|c|}{\begin{tabular}{c|} 
from \\
EL-Marg
\end{tabular}} & \begin{tabular}{|c|} 
to \\
Ghamra
\end{tabular} & $\begin{array}{c}\text { from } \\
\text { Helwan }\end{array}$ & \multicolumn{2}{|c|}{$\begin{array}{c}\text { to } \\
\text { Mar-gergis }\end{array}$} & \multicolumn{2}{|c|}{\begin{tabular}{c|c} 
from & \\
Ahmed & \\
Orabi & \\
\end{tabular}} & $\begin{array}{c}\text { to } \\
\text { Hada'k } \\
\text { Helwan } \\
\end{array}$ \\
\hline & $\mathbf{x}$ & $\mathbf{y}$ & $\mathbf{z}$ & $\mathbf{x}$ & $\mathbf{y}$ & $\mathbf{z}$ & $\mathbf{x}$ & $\mathbf{y}$ & $\mathbf{z}$ \\
\hline Acceleration Dose (Dk) & 20.35 & 42.44 & 22.49 & 16.69 & 48.35 & 48.37 & 27 & 44.59 & 22.05 \\
\hline $\begin{array}{l}\text { Equivalent daily static } \\
\text { compressive stress (Sed) }\end{array}$ & \multicolumn{3}{|c|}{2.53} & \multicolumn{3}{|c|}{3.10} & \multicolumn{3}{|c|}{2.48} \\
\hline Risk factor $(\mathrm{R})$ & \multicolumn{3}{|c|}{3.63} & \multicolumn{3}{|c|}{4.46} & \multicolumn{3}{|c|}{3.56} \\
\hline
\end{tabular}

Muscle fatigue also occurs as the muscles try to react to the vibrational energy to maintain balance and protect and support the spinal column. But these are often too slow as muscular and nervous system cannot react fast enough to the shocks and loads being applied to the body.

\section{Conclusion}

In this study, it was found that most of the frequencyweighted RMS accelerations of the metro were within the "potential health risks" zone according to ISO 2631-1:1997. It was clear that the metro passengers were exposed to serious magnitudes of WBV. That WBV gained by human body increased when the duration of vibration exposure and the total metro trips experienced by the subject enlarged. Empirical studies showed that there was a relation between an occupational vehicles and whole-body vibration that lead to musculoskeletal disorders.

When using ISO 2631-1 (1997) and European Directive 2002 it can be seen that about ninety five percent of the three trips results fall within or below the health guidance caution zone (HGCZ) indicating less risk. However, when ISO 2631-5 (2004) is used it can be seen that all results fall above the
HGCZ indicating a high probability to risk. It can therefore be stated that health risk assessment based on $S_{\text {ed }}$ parameter of ISO 2631-5 (2004) standard is more conservative than risk assessment based on the VDV in the presence of shocks. This is due to the fact that the ISO 2631-5 (2004) standard takes into account the transient and high magnitude shocks events which are handled better than the ISO 2631-1 (1997) standard.

The term musculoskeletal disorder refers to conditions that involve the nerves, tendons, muscles and supporting structures of the body [11]. Exposure to WBV is another occupational risk factor that may cause LBP in participants of occupational vehicles [6]. Due to this high value of the frequency-weighted RMS, large relative displacement between the lumbar vertebrate take place. Therefore, it was likely that the lumbar tract of passenger's spine was overloaded by mechanical vibration.

Therefore, health and safety management should be carried out to prevent adverse health effects in metro passengers. Seats with arm rests, lumbar support, an adjustable seat back and an adjustable seat pan are also useful for correcting passenger surfaces to reduce vibration at the source. 
In particular, reduction of WBV in metro and shortening of the duration of using metro as transportation mean lead to reduce the duration of WBV exposure.

\section{ACKNOWLEDGMENTS}

This research paper could not have been written without the encouragement and support of: teachers, family, friends, and in essence, all sentient beings. Especially, please allow me to dedicate my acknowledgment of gratitude toward the following significant advisors and contributors:

First and foremost, I would like to thank Prof. Mohamed El Adawy and Dr. Shahira Habashy for their most support and encouragement. They kindly read my paper and offered invaluable detailed advices on grammar, organization, and the theme of the paper. Finally, I sincerely thank to my family, and friends, who provide the advice and financial support. The product of this research paper would not be possible without all of them.

\section{REFERENCES}

[1] M. J. Griffin, 1990. "Handbook of Human Vibration", London Academic Press, ISBN: 0123030412, pp: 171220 .

[2] Garg, and J. S. Moore, 1992. "Epidemiology of lowback pain in industry", Occup. Med., 7: 593-60.

[3] V. M. W. Tulder, B.W. Koes, and L.M. Bouter, 1995. "A cost-of-illness study of back pain in the Netherlands Pain", 62: 233-240.

[4] D.G. Wilder, and M.H. Pope, 1996. "Epidemiological and etiological aspects of low back pain in vibration environments-an update", Clin. Biomech., 11: 61-73. DOI: 10.1016/0268- 0033(95)00039-9.

[5] Burdorf, and G. Sorock, 1997. "Positive and negative evidence of risk factors for back disorders", Scand. J. Work Environ. Health, 23: 243-256.

[6] M. Bovenzi, and C.T.J. Hulshof, 1999. "An updated review of epidemiologic studies on the relationship between exposure to whole-body vibration and low back pain", Int. Arch. Occup. Environ. Health, 72: 351-365. DOI: $10.1007 / \mathrm{s} 004200050387$.

[7] S. Lings, and C. Leboeuf-Yde, 2000. "Whole-body vibration and low back pain", "A systematic, critical review of the epidemiological literature", Int. Arch. Occup. Environ. Health, 73: 290- 297. DOI:10.1007/s004200000118.

[8] G. Waddell, and A.K. Burton, 2000. "Occupational health guidelines for the management of low back pain at work": Evidence review. Occup. Med., 51: 124-135. DOI: 10.1093/occmed/51.2.124.
[9] ISO, 1997. "Evaluation of human exposure to whole body vibration". International Organization for Standardization. Ref. No. ISO 2631-1.

[10] C. Drugă, D. Barbu, and S. Lache, 2007. "Vibration and the Human Body", Annals of the Oradea University. Fascicle of Management and Technological Engineering, Volume VI (XVI).

[11] B.P. Bernard, 1997. "Musculoskeletal disorders and workplace factors: A critical review of epidemiologic evidence for work-related musculoskeletal disorders of the neck, upper extremity and low back", National Institute for Occupational Safety and Health, Cincinnati, OH.visited on http://www.cdc.gov/niosh/docs/97-141/

[12] "Directive 2002/44/EC of the European Parliament and of the Council of 25 June 2002". Official Journal of the European Communities.

[13] Australian Standard AS 2670.1:2001 "Evaluation of human exposure to whole-body vibration - Part 1: General requirements."

[14] Diogo Koenig, Marilda S. Chiaramonte and Alexandre Balbinot, 2008. "Wireless Network for Measurement of Whole-Body Vibration", Sensors 2008, 8, 3067-3081; DOI: $\quad 10.3390 / \mathrm{s} 8053067 . \quad$ visited on www.mdpi.org/sensors

[15] International Standards Organization (2004). Mechanical vibration and shock-"Evaluation of human exposure to whole-body vibration-Part 5: Method for evaluation of vibration containing multiple shocks". ISO 2631-5: (E).

[16] "Whole Body Vibration", 2005. Occupational Health Clinics for Ontario Workers Inc. HAMILTON 848 Main Street East Hamilton, ON L8M 1L9 (905)-549-2552.

[17] Nabih ALEM, 2005. "Application of the New ISO 26315 to Health Hazard Assessment of Repeated Shocks in U.S.Army Vehicles", Industrial Health, 43, 403412.U.S. Army Aeromedical Research Laboratory, Fort Rucker, Alabama 36362-0577, USA.

[18] T. Eger, J. Stevenson, P.-E' . Boileau, and A. Salmoni, VibRG, 2008. "Predictions of health risks associated with the operation of load-haul-dump mining vehicles: Part 1- Analysis of whole-body vibration exposure using ISO 2631-1 and ISO-2631-5 standards", International Journal of Industrial Ergonomics 38 (2008) 726-738. Available online at www.ScienceDirect.com.

[19] A.R. Ismail, M.Z. Nuawi, C.W. How, N.F. Kamaruddin, M.J.M. Nor and N.K. Makhtar, 2010. "Whole Body Vibration Exposure to Train Passenger", American Journal of Applied Sciences 7 (3): 352-359. ISSN 15469239. (C) 2010Science Publications.

[20] "Guide to good practice on Whole-Body Vibration", 2006. WBV Good practice Guide v6.7g English 070606.doc. 